\title{
ENERGY USE EFFICIENCY OF ELECTRIC AUTOMOBILE DEPENDING ON TRANSMISSION GEAR RATIO
}

Dainis Berjoza, Vilnis Pirs, Inara Jurgena, Janis Laceklis-Bertmanis

Latvia University of Life Sciences and Technologies, Latvia

dainis.berjoza@1lu.lv, vilnis.pirs@1lu.lv, inara.jurgena@1lu.lv, janis.bertmanis@1lu.lv

\begin{abstract}
When converting an internal combustion vehicle to electric power, it is important to choose the right transmission gear ratio to ensure optimum performance of the vehicle. A converted automobile is usually equipped with a standard transmission gearbox, while the motor control block is programmed for one particular gear. During the operation of an electric automobile, the gears could be shifted, when the automobile is stopped, as the clutch is not used by the electric automobile. In choosing a gear ratio, a priority could be to ensure good dynamic performance or high speed achievement. However, one of the most important parameters is energy consumption and the distance covered per charge. After identifying the optimum gear ratio or the gear to be used, the unused gears of the transmission gearbox of the converted vehicle could be dismantled, thereby reducing the weight of the vehicle and increasing the transmission gear ratio. A converted Renault Clio with a $96 \mathrm{~V}$ battery system and a standard 5-speed transmission gearbox was road tested. The experimental data speed, change in voltage and current, battery temperature and measurement time were recorded by a multichannel data logger. The road tests were carried out at constant speeds -50 and $90 \mathrm{~km} \cdot \mathrm{h}^{-1}$. The road tests showed that energy consumption by the electric automobile in the fourth gear at $50 \mathrm{~km} \cdot \mathrm{h}^{-1}$ was the lowest, consuming a power of $5.86 \mathrm{~kW}$, while in the fourth gear at $90 \mathrm{~km} \cdot \mathrm{h}^{-1}$ it consumed $15.43 \mathrm{~kW}$.
\end{abstract}

Keywords: electric vehicle, current, voltage, constant speed.

\section{Introduction}

The trend of replacing internal combustion vehicles with electric ones is observed in the world. Electric automobiles have not only a different source of energy and batteries, but also other structural elements. One of such elements is transmission. Internal combustion automobiles reach maximum power output and torque at a high rotation frequency of the crankshaft of the engine. Usually, maximum power output is reached at the maximum rotation frequency of the crankshaft, while maximum torque is reached at a medium rotation frequency. For this reason, to ensure a performance regime of the motor that corresponds to the lowest fuel consumption and optimum power output and torque, it is necessary to use a gearbox or another torque-changing mechanism, e.g. a hydro transformer.

Usually, serial electric automobiles are not equipped with a changeable gearbox or a hydro transformer. The standard gearbox of an internal combustion vehicle is used, if the vehicle is converted from an internal combustion vehicle to an electric vehicle. In this case, an important parameter is the right transmission gear ratio, as the controller of the motor is programmed for a particular transmission gear ratio. Other transmission gear ratios could be also used to drive the vehicle, yet such important parameters as regenerative braking efficiency and motor rotation frequency readings on the gauge panel might considerably differ from the parameters programmed. The research put forward a hypothesis: the chosen transmission gear ratio can affect the electrical energy consumption, current and power consumption of the electric vehicle.

Further, the research analyses similar research investigations into electric vehicles. The research also developed an energy management system for a hybrid automobile. A reduction in energy consumption was achieved by using ultracapacitors and the regenerative braking system. The system could be equipped with various kinds of batteries. The research developed a mathematical model and performed road tests. The road tests identified and analysed such electrical parameters as the change in battery voltage and current. The application of regenerative braking yielded a $28.6 \%$ better result than the standard system did [8].

Plug-in hybrid electric vehicles (PHEV) have been extensively researched. The system developed ensures optimum battery performance depending on the battery charging temperature and the battery charge level. Mathematical models for the main automobile systems - the motor, controller and the generator - as well as for automobile motion have been developed. Changes in current and voltage were recorded in various driving cycles [7]. 
A simulation of the transmission was done by using a plug-in hybrid automobile with a $40 \mathrm{~kW}$ motor. The end gear ratio for the automobile was $i_{0}=3.5$. The automobile was equipped with two gearboxes - one with continuously variable gearing in the range from 4 to 0.6 and the second one had four transmission gear ratios: $2.5,1.5,1$ and 0.8 . The lowest energy consumption was demonstrated by the automatic gearbox, which was $5.3 \%$ lower than if using no gearbox. The 4-speed gearbox had the second best energy consumption result, which was $4.4 \%$ lower than if using no gearbox. Using a 2speed gearbox, the energy consumption was $2.8 \%$ lower than if using no gearbox. The research also examined energy consumption in six diverse driving cycles, identifying a $24.1 \%$ difference in energy consumption. It follows that a driving regime can considerably affect the energy consumption by the electric automobile, depending on the kind of the gearbox and the gear shift algorithm [9].

Research studies on a converted electric automobile have been done as well. A methodology for experimental research to identify the performance parameters by means of a data logger was developed. Road tests identified changes in battery voltage, current and power consumed in urban and non-urban driving. The road tests identified the maximum current when accelerating in non-urban driving, which reached $450 \mathrm{~A}$, while in urban driving it was $250 \mathrm{~A}$. Even though the regenerative current in non-urban driving reached $140 \mathrm{~A}$, which was a twofold higher current than that in urban driving, the proportion of this kind of driving in urban driving was low; consequently, no significant increase in the distance covered was observed. Smooth driving at $50 \mathrm{~km} \cdot \mathrm{h}^{-1}$ consumed a power of $6.7 \mathrm{~kW}[1]$.

Due to the fact that the power and torque characteristic curves of an electric motor differ from those of an internal combustion engine, the transmission configuration could be different as well. The literature suggests various transmission solutions: using a gearbox, setting the electric motors by the wheels or using a single-speed transmission. However, if wishing a better dynamics performance of a vehicle, particularly if it is equipped with a low power electric motor, one can use a few-speed gearbox as well $[4 ; 5]$. The right choice of a gear ratio does not considerably affect the power consumed; however, it can ensure better acceleration dynamics. This allows achieving both a better dynamics performance of a vehicle and lower loads on the batteries, wiring and the controller [3].

Gear shifting was also optimised by using dynamic programming for optimal hybridization in parallel hybrid electric vehicles. The research developed a mathematical model for vehicles, a fuel consumption map for an internal combustion engine and an efficiency map for an electric motor that shows the maximum and minimum torque. The model used a battery efficiency factor in the range of 0.9-1.0. The model was tested in eight different drive cycles [10].

\section{Materials and methods}

The road tests used a converted Renault Clio automobile. The automobile was equipped with a standard 5-speed gearbox. Shifting the gears is possible only when the automobile is stopped, as the clutch is not used to engage the motor with the transmission. A $30 \mathrm{~kW}$ electric motor was installed on the automobile. It was powered by a $96 \mathrm{~V}$ system, which was comprised of 30 lithium-iron hybrid batteries with a capacity of $100 \mathrm{Ah}$. The maximum speed of the automobile was $120 \mathrm{~km} \cdot \mathrm{h}^{-1}$, while the average range per charge was $60 \mathrm{~km}$. The parameters of the automobile's controller were programmed for the third gear. Transmission gear ratios for the gearbox $i_{k}$, the end gear ratio $i_{0}$ and the total transmission gear ratio are given in Table 1. It also shows the data on electric motor rotation frequency $n_{e}$ at the speeds, at which the electric automobile was road tested, taking into consideration the calculated kinematic radius of the wheels $r_{k}=0.283 \mathrm{~m}$ for tyres $165 / 70 \mathrm{R} 14$.

Table 1

Transmission gear ratios and the calculated motor rotation frequency for the electric automobile

\begin{tabular}{|c|c|c|c|c|c|c|}
\hline \multirow{2}{*}{ No } & \multirow{2}{*}{ Characteristics } & \multicolumn{5}{|c|}{ Gears } \\
\cline { 3 - 7 } & Gearbox transmission ratio $i_{k}$ & $\mathbf{1}^{\text {st }}$ & $\mathbf{2}^{\text {nd }}$ & $\mathbf{3}^{\text {rd }}$ & $\mathbf{4}^{\text {th }}$ & $\mathbf{5}^{\text {th }}$ \\
\hline 1 & End gear ratio $i_{0}$ & 1.864 & 1.321 & 1.029 & 0.821 \\
\hline 2 & Transmission ratio $i_{t}$ & 13.679 & 7.579 & 5.374 & 4.186 & 3.337 \\
\hline 3 & $n_{e}$ at $\mathrm{v}=50 \mathrm{~km} \cdot \mathrm{h}^{-1}$ & 6413 & 3553 & 2519 & 1963 & 1564 \\
\hline 4 & $n_{e}$ at $\mathrm{v}=90 \mathrm{~km} \cdot \mathrm{h}^{-1}$ & 11543 & 6395 & 4535 & 3533 & 2816 \\
\hline 5 &
\end{tabular}


As shown in Table 1, achieving the driving regime in the first gear requires too high motor rotation frequency, which is limited by controller settings. For this reason, first gear was not used in the road tests.

A data logger HOLUX GP Sport 245 was used to accurately control the speed of the electric automobile. The logger had $512 \mathrm{kB}$ memory, operating temperature from $+10^{\circ} \mathrm{C}$ to $+50^{\circ} \mathrm{C}$. The logger was attached to the gauge panel for visual control during the road tests.

A data logger Graphtec GL220 was used to save the electrical parameters recorded (Fig. 1). The logger could save data at a sampling interval from $10 \mathrm{~ms}$ to $24 \mathrm{~h}$. The equipment used a $4.3 \mathrm{inch} \mathrm{LCD}$ display. Electricity was supplied from a 8.5-24 V external source. During the road tests, the logger was connected to the $12 \mathrm{~V}$ board system power supply of the electric automobile.

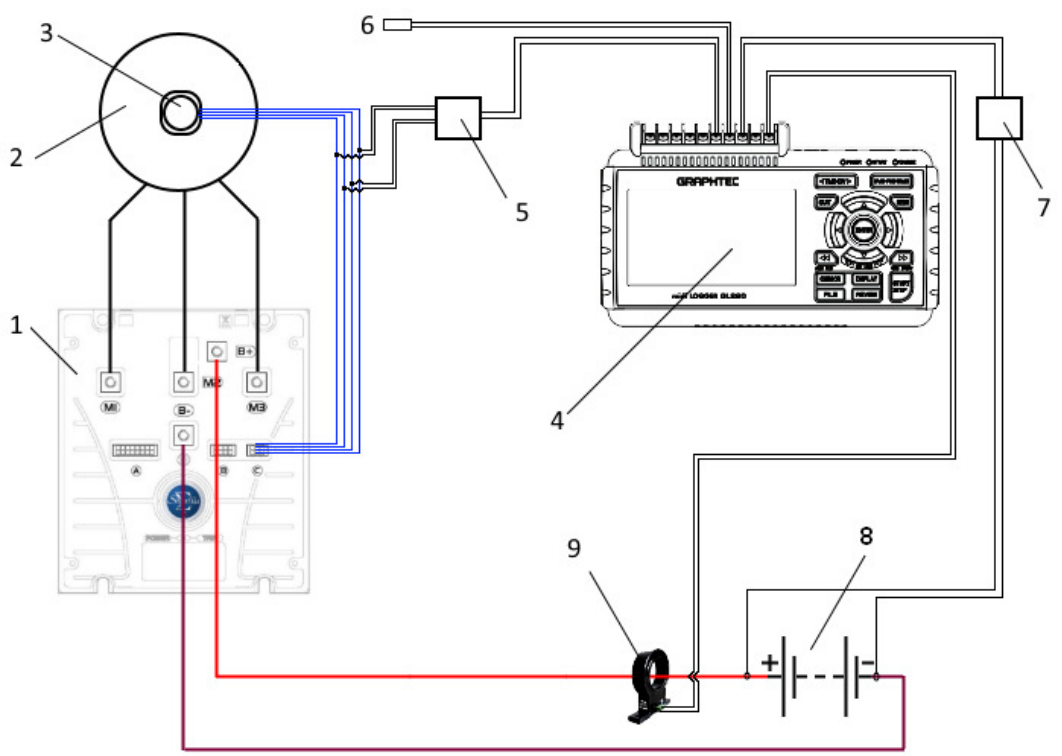

Fig.1. Scheme for connecting experimental equipment: 1 - motor controller; 2 - electromotor; 3 - electromotor speed sensor; 4 - data logger; 5 - frequency-voltage converter; 6 - temperature sensor.; 7 - voltage divider; 8 - $96 \mathrm{~V}$ accumulator; 9 - current sensor

The road tests were carried out on the general road E77 Jelgava-Riga. The road surface was in good condition; the average rolling resistance coefficient was 0.010-0.011 [2]. During the road tests, the ambient air temperature was $+10^{\circ} \mathrm{C}$; there was no precipitation and the asphalt was dry.

The road tests were performed by two operators. One operated the automobile and accurately maintained the driving regime, while the second one activated the logger and saved the data in individual data fails. Every road test replication lasted for 30 seconds. To accurately record the driving regime and the replications, they were numbered in sequence. The measurements were made in the 25 gears at two constant speeds: $50 \mathrm{~km} \cdot \mathrm{h}^{-1}$ and $90 \mathrm{~km} \cdot \mathrm{h}^{-1}$. Since it was possible to achieve none of the planned speeds in the first gear, this gear was not used. It was not possible to achieve a speed of $90 \mathrm{~km} \cdot \mathrm{h}^{-1}$ in the second gear in the road tests. Five replications were performed for every driving regime.

To exclude casual factors, the first road test replication was performed in all selected gears - from 2 to $5-$, which was followed by the next replication in all selected gears.

\section{Results and discussion}

An example of the saved data acquired in the road tests performed in the third gear at $90 \mathrm{~km} \cdot \mathrm{h}^{-1}$ is given in Figure 2. The power transmitted to the wheels in all the gears under the same motion conditions has to be the same. The motor power output of the automobile operated in diverse gears could differ under the same motion conditions, as every gear has a different efficiency factor. Besides, the rotation frequency of the motor, which is necessary for achieving the required motor power output in various gears, also affects the motor power. Efficiency factors are different at various rotation frequencies of the motor. 


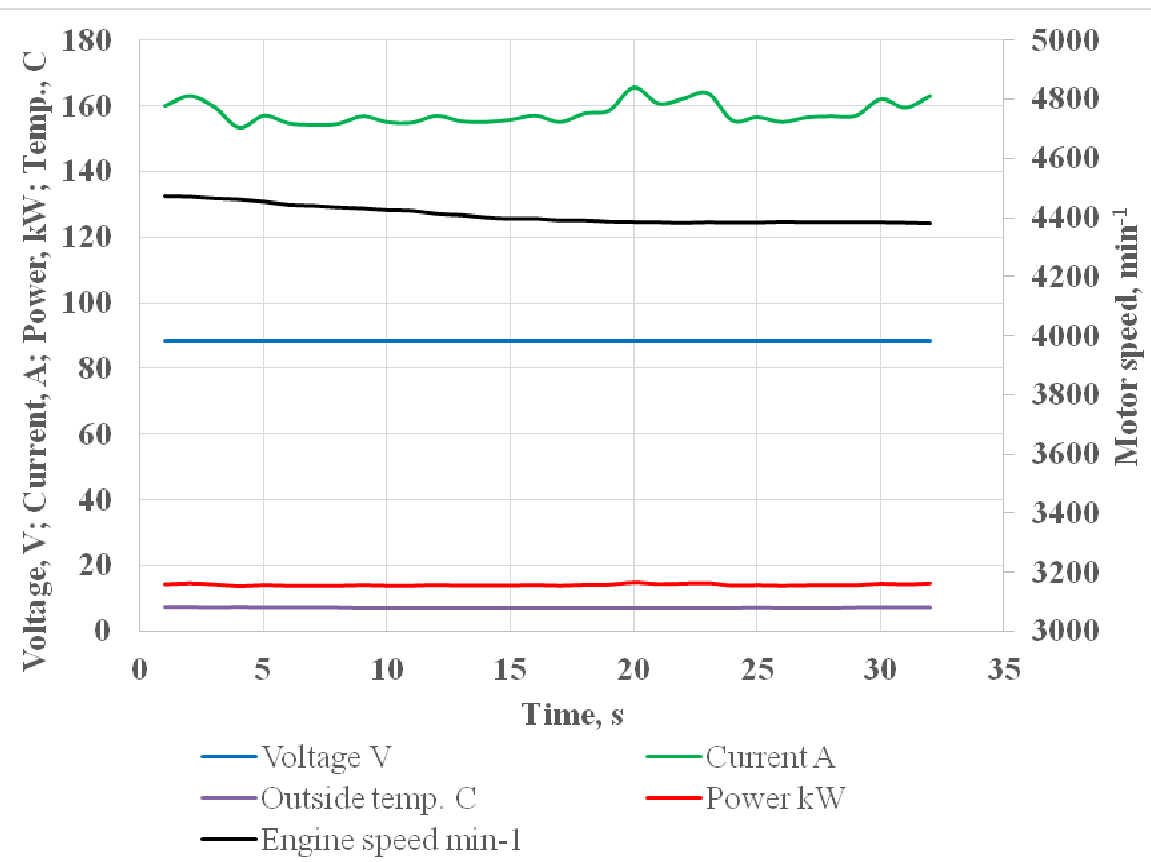

Fig. 2. Results of road tests performed in third gear at $90 \mathbf{~ k m} \cdot \mathbf{h}^{-1}$

After the road tests were completed, the data were exported from the logger to a PC for processing. The research calculated the average current, energy consumed and motor power output for two speed regimes. The data allowed calculating the electric automobile's energy consumption per km distance covered for both speed regimes in all the gears used in the road tests. Using data from an earlier series of road tests done in the changing speed regime in third gear, the research calculated the average energy consumption by the electric automobile Renault Clio at $0.135 \mathrm{kWh} \cdot \mathrm{km}^{-1}$ in urban driving and at $0.155 \mathrm{kWh} \cdot \mathrm{km}^{-1}$ in non-urban driving [1].

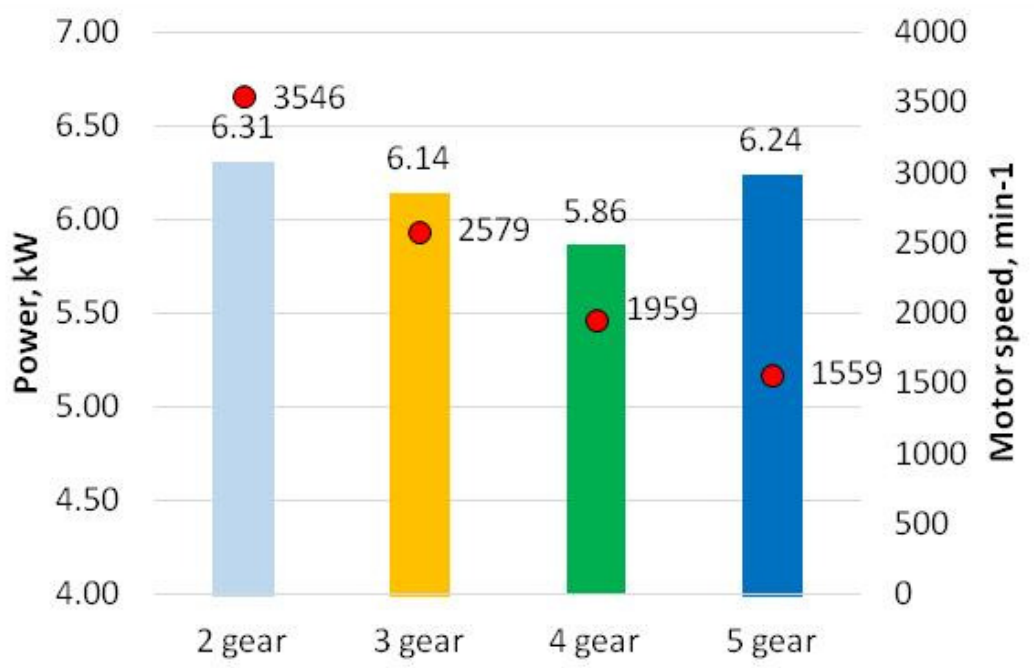

Fig. 3. Power and motor rotation frequency at $50 \mathrm{~km} \cdot \mathbf{h}^{-1}$

Road testing the electric automobile at $50 \mathrm{~km} \cdot \mathrm{h}^{-1}$, the rotation frequency of the motor changed in the range from $3546 \mathrm{~min}^{-1}$ to $1559 \mathrm{~min}^{-1}$. Its power consumption could be affected by the transmission efficiency factor, the motor efficiency factor and the invertor efficiency factor. The transmission efficiency factor differs depending on the gear chosen. The motor efficiency factor, according to the manufacturer graphs [11], has to be almost constant in the entire range of frequencies, and the total energy consumption could not be affected. The highest power consumed was registered in the second gear, at $6.31 \mathrm{~kW}$ (Fig. 3). This might be explained by the fact that the efficiency factor for the second gear is lower than that for the other gears $\left(i_{2}=1.864\right)$. The power consumption in the fourth gear was $4.8 \%$ lower than that in the third gear and $6.5 \%$ lower than that in the fifth gear. From the perspective 
of power consumption, it is advised to choose the fourth gear in urban driving; however, to make an objective decision on the choice of a gear, it is necessary to carry out additional road tests to identify the parameters of dynamism or acceleration for all gears. The dynamism of the automobile in urban driving in the fourth gear considerably declines.

Road testing the electric automobile in the second gear did not allow achieving the experimental speed of $90 \mathrm{~km} \cdot \mathrm{h}^{-1}$, as the motor rotation frequency limiter engaged. For this reason, the automobile was road tested in the highest three gears. When driving in the fifth gear at $2800 \mathrm{~min}^{-1}$, the motor almost achieved the highest power output in this range of rotation frequencies. Consequently, the power consumed in this regime was the highest, $10.9 \%$ higher than in the fourth gear and $2.9 \%$ higher than in the third gear (Fig. 4). Fifth gear gave almost no possibility to accelerate. When driving in the third gear, the motor operated within the optimum range of the power curve - the power output was almost maximal and there was a good possibility for acceleration. However, due to the transmission efficiency factor, the power consumption in the fourth gear was lower. To do an optimum choice of a gear for this driving regime (non-urban driving), it is advised to do road tests in various gears.

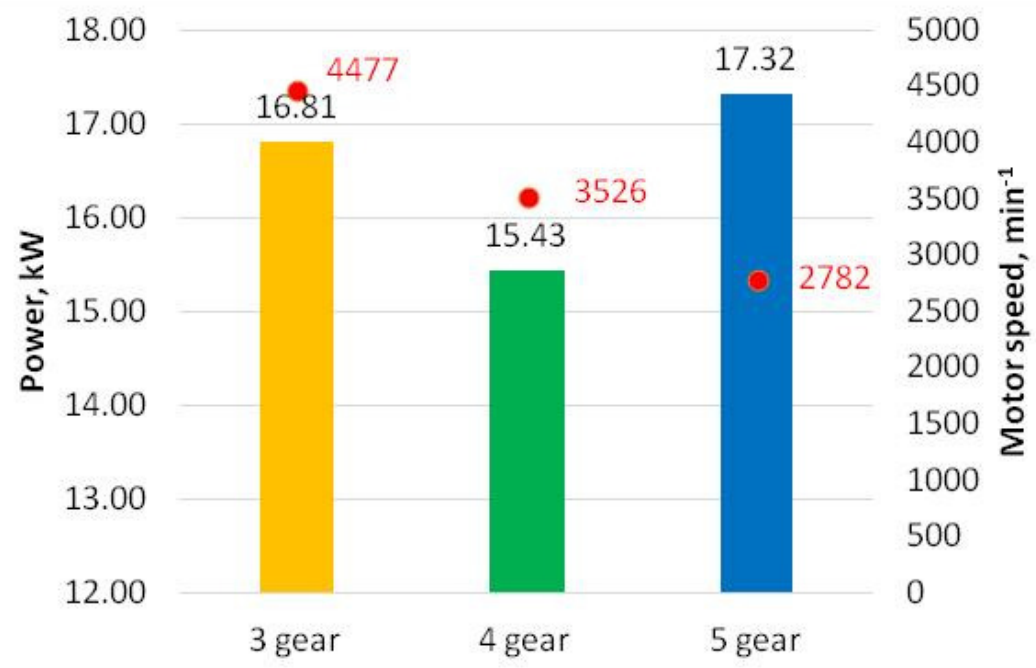

Fig. 4. Power and motor rotation frequency at $90 \mathrm{~km} \cdot \mathrm{h}^{-1}$

An analysis of energy consumption in urban driving in the third gear revealed that it was $1.23 \mathrm{kWh} \cdot \mathrm{km}^{-1}$ (Fig. 4). Combining the dynamism and efficiency of an electric automobile in urban driving, it is useful to accelerate the electric automobile in the second gear and then shift to the fourth gear. However, it is difficult for the experimental automobile to do it, as the transmission does not use the clutch. In urban driving, the lowest energy consumption was identified when driving in the fourth gear. The energy consumption in the fourth gear was $8.6 \%$ lower than that in the third gear and $10.9 \%$ lower than in the fifth gear.

For electric automobiles converted from internal combustion ones, scientists have developed a calculation methodology for the conversion algorithm, which takes into account the rolling resistance, air resistance, gradient resistance and inertia resistance. The calculation example is given for an electric automobile Toyota Kijang Super, the structure of which is similar to that of the electric automobile examined in the present research in terms of the technical parameters. The most significant difference lies in the batteries, as the mentioned algorithm was intended for lead batteries, whereas the road-tested electric automobile was equipped with lithium-iron hybrid batteries. However, the algorithm does not analyse the principles of how to determine the gear ratio experimentally or analytically [6].

From the perspective of the energy consumption, it is useful to choose the fourth gear, yet this gear does not ensure sufficient dynamics for an electric automobile. Higher dynamics of the electric automobile could be achieved by equipping it with a simple 2- or 3-speed gearbox that could be capable of ensuring an optimum load for the motor, lower energy consumption and better dynamics performance. Gear-shifting in such a gearbox has to be automatic in order to facilitate the control of the electric automobile. 


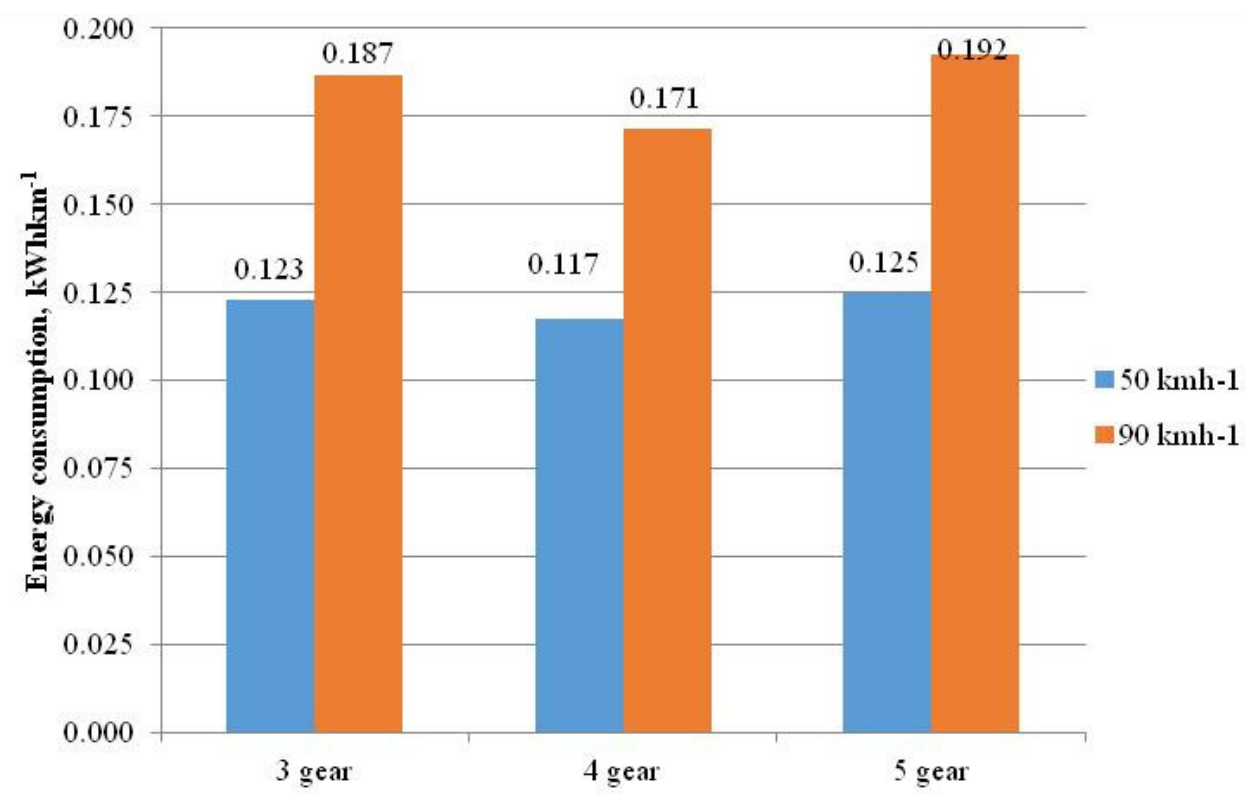

Fig. 5. Energy consumption at $50 \mathrm{~km} \cdot \mathrm{h}^{-1}$ and $90 \mathrm{~km} \cdot \mathrm{h}^{-1}$

\section{Conclusions}

1. The research developed and approbated a methodology for identifying average power output and energy consumption in various driving regimes by using a data logger.

2. Depending on the gear, energy consumption and power output could be affected by the motor efficiency factor, transmission efficiency factor and the invertor efficiency factor. The transmission efficiency factor, which was the highest for the gear ratios close to $1\left(i_{4}=1.029\right)$, made the largest effect on the power consumed.

3. Road testing the electric automobile at $50 \mathrm{~km} \cdot \mathrm{h}^{-1}$, the energy consumption in the fourth gear was the lowest, at $5.86 \mathrm{~kW}$, which was $4.8 \%$ lower than that in the third gear and $6.5 \%$ lower than in the fifth gear.

4. The highest power consumption was in the second gear at $50 \mathrm{~km} \cdot \mathrm{h}^{-1}, 6.31 \mathrm{~kW}$, which might be explained by the fact that the efficiency factor for the second gear was the lowest.

5. From the perspective of the power consumption, it is advised to choose the fourth gear in urban driving; however, the dynamism of the automobile in the fourth gear considerably declines.

6. At $90 \mathrm{~km} \cdot \mathrm{h}^{-1}$, the highest power consumption was in the fifth gear, $17.32 \mathrm{~kW}$, as the motor achieved the maximum power output in the respective range of rotation frequencies. The possibility to accelerate the automobile in this gear was minimal.

7. Just like at a speed of $50 \mathrm{~km} \cdot \mathrm{h}^{-1}$, at a speed of $90 \mathrm{~km} \cdot \mathrm{h}^{-1}$ too, the lowest power consumption was in the fourth gear, $15.43 \mathrm{~kW}$, which was associated with the highest efficiency factor of the gearbox. In this gear, the motor operated in the range of maximum rotation frequencies of the power curve.

8. To make an objective decision on the choice of a gear for an electric automobile, it is necessary to do research on the parameters of acceleration in all gears, as well as to road test the electric automobile in the 3-5 gears in non-urban driving.

9. The energy consumption both in urban and in non-urban driving in the fourth gear was the lowest, $0.117 \mathrm{kWh} \cdot \mathrm{km}^{-1}$ and $0.171 \mathrm{kWh} \cdot \mathrm{km}^{-1}$, respectively, yet the choice of this gear could affect the dynamism parameters of the electric automobile.

10. To ensure good performance of an electric automobile in terms of dynamics, electrical energy consumption and motor load, it is advised to equip the electric vehicle with a 2- or 3-speed gearbox that could enhance the performance of the electric vehicle.

\section{References}

[1] Berjoza D., Pirs V., Jurgena I. Investigation into the performance characteristics of electric automobiles by means of a data logger. Agronomy Research, Nr. 16, 2018. 
[2] Bosch Automotive Handbook. Seventh edition. Wiley, 2008. 1199 p.

[3] Cristomi E., Shorten R., Studli S., Wirth F. Electric and Plug-in-Hybrid Vehicle Networks. Optimization and Control. CRC Press: Taylor \& Francic Group, 2018. 242 p.

[4] Ehsani M., Gao Y., Gay S. E., Emadi A. Modern Electric, Hybrid Electric, and Fuel Cell Vehicles. Fundamentals, Theory, and Design. CRC Press, 2005. 385 p.

[5] Ehsani M., Gao Y., Longo S., Ebrahimi K. M. Modern Electric, Hybrid Electric, and Fuel Cell Vehicles. Third Edition. CRC Press: Taylor \& Francic Group, 2018. 546 p.

[6] Kaleg S., Hapid A., Kurnia M.R. Electric Vehicle Conversion Based on Distance, Speed and Cost Requirements. Energy Procedia, vol.68, 2015, pp.446-454.

[7] Li S.G., Sharkh S. M., Walsh F. C. etc. Energy and battery management of a plug-in series hybrid electric vehicle using fuzzy logic. IEEE Transactions on Vehicular Technology, vol 60, Nr.8, 2011, pp. 3571- 3585.

[8] Moreno J, Ortúzar M.E., Dixon J. W. Energy-management system for a hybrid electric vehicle, using ultracapacitors and neural networks. IEEE Transactions on Industrial Electronics, vol. 53, 2006, pp. 614-623.

[9] Ren Q., Crolla D., Morris A. The effect of Transmission Design on Electric Vehicle (EV) Performance. The Journal of Energy and Power Engineering, vol.4, Nr.3, 2010, pp. 46-51.

[10] Sundstrom O., Guzzelle L., Soltic P. Optimal hybridization in two parallel hybrid electric vehicles using dynamic programming. Proceedings of the 17th World Congress The International Federation of Automatic Control, July 6-11, 2008, Seoul, Korea, pp. 4642-4647.

[11] HPEVS AC-50 Imperial Peak Graph. EV WEST. Top. Catalog. Motors. AC-50-96. [online] [28.03.2018]. Available at: // http://www.evwest.com/catalog/product_info.php?products_id $=83$ 